\title{
Molecular alterations in key-regulator genes among patients with T4 breast carcinoma
}

\author{
Bruno Massidda ${ }^{1}$, MariaCristina Sini ${ }^{2}$, Mario Budroni ${ }^{3}$, Francesco Atzori ${ }^{1}$, MariaCristina Deidda ${ }^{1}, V_{a l e r i a ~ P u s c e d d u}{ }^{1}$, \\ MariaTeresa Perra ${ }^{4}$, Paola Sirigu ${ }^{4}$, Antonio Cossu ${ }^{5}$, Grazia Palomba ${ }^{2}$, MariaTeresa Ionta', Giuseppe Palmieri ${ }^{*}$
}

\begin{abstract}
Background: Prognostic factors in patients who are diagnosed with T4 breast carcinomas are widely awaited. We here evaluated the clinical role of some molecular alterations involved in tumorigenesis in a well-characterized cohort of T4 breast cancer patients with a long follow-up period.

Methods: A consecutive series of 53 patients with T4 breast carcinoma was enrolled between 1992 and 2001 in Sardinia, and observed up for a median of 125 months. Archival paraffin-embedded tissue sections were used for immunohistochemistry (IHC) and fluorescence in situ hybridization (FISH) analyses, in order to assess alterations in expression levels of survivin, p53, and pERK ${ }_{1-2}$ proteins as well as in amplification of CyclinD1 and h-prune genes. The Kaplan-Meier and Cox regression methods were used for survival assessment and statistical analysis.
\end{abstract}

Results: Overall, patients carrying increased expression of $\mathrm{pERK}_{1-2}(p=0.027)$ and survivin $(p=0.008)$ proteins as well as amplification of $h$-prune gene $(p=0.045)$ presented a statistically-significant poorer overall survival in comparison with cases found negative for such alterations. After multivariate analysis, the pathological response to primary chemotherapy and the survivin overexpression in primary carcinoma represented the main parameters with a role as independent prognostic factors in our series.

Conclusions: Although retrospective, our study identified some molecular parameters with a significant impact on prediction of the response to therapy or prognosis among T4 breast cancer patients. Further large prospective studies are needed in order to validate the use of such markers for the management of these patients.

\section{Background}

Since the staging systems of breast cancer were introduced during the course of the last century, the involvement of the skin has always been considered a morphologic characteristic leading to the classification of the tumour into the highest non-metastatic disease stage. In the current edition of the International Union Against Cancer (UICC)/American Joint Committee on Cancer (AJCC) TNM staging system [1], primary breast cancers with extension to the skin are classified as T4. Patients with T4 carcinomas of any type, with or without lymph node involvement, and without distant metastases (T4 N0-2 M0), are classified as disease stage IIIB. According to this system, the breast carcinoma with skin involvement is included in stage III

\footnotetext{
* Correspondence: gpalmieri@yahoo.com

${ }^{2}$ Institute of Biomolecular Chemistry-National Research Council (CNR), Sassari, Italy

Full list of author information is available at the end of the article
}

and may be considered as locally-advanced breast cancer (LABC) [1-3].

In addition to the tumour size and the axillary lymph node involvement, other well-established prognostic factors currently used in breast cancer include histological subtype or grade, estrogen (ER) and progesterone (PR) receptor status, HER2 amplification, and Ki67 proliferation index $[4,5]$. Novel tumour markers with potential clinical utility are thus awaited.

The molecular mechanisms underlying locallyadvanced breast carcinomas are largely unknown. A distinct gene-expression profile has been described for T3/ T4 tumours in comparison to the gene-expression pattern of T1/T2 tumours [6], suggesting that a distinct biological behaviour may characterize initial $v s$. locallyadvanced breast carcinomas. The mitogen activated protein kinase (MAPK) pathway, a major signalling cascade involved in the control of cell growth and proliferation, has been indicated to play a role in the intracellular
C Biomed Central

(c) 2010 Massidda et al; licensee BioMed Central Ltd. This is an Open Access article distributed under the terms of the Creative Commons Attribution License (http://creativecommons.org/licenses/by/2.0), which permits unrestricted use, distribution, and reproduction in any medium, provided the original work is properly cited. 
signalling process of breast carcinomas [7-9]. The ERK12 proteins, which represent the final components of such a signalling kinase cascade, have been found to be activated through phosphorilation $\left(\mathrm{pERK}_{1-2}\right)$ in human cancer and implicated in rapid malignant cell growth, mostly as a consequence of mutations in upstream components of the pathway $[10,11]$. Presence of $p E R K_{1-2}$ could be thus considered as a marker for the increased activity of ERK1-2, which may induce cell proliferation, rapid cancer cell growth, and resistance to apoptosis [10]. Moreover, a genomic instability with an increased number of copies of the CyclinD1 gene, which encodes a component of the $\mathrm{p} 16^{\mathrm{CDKN} 2 \mathrm{~A}}-\mathrm{RB}$ pathway functionally interacting with the MAPK pathway $[12,13]$, has been described to promote a deregulation of the cell cycle with subsequent induction of an uncontrolled cell proliferation and tumour growth [14]. Nevertheless, the p53 protein represent the final effector of the $\mathrm{p} 14^{\mathrm{CDKN} 2 \mathrm{~A}}$ MDM2 pathway; in majority of human cancers, the TP53 gene is functionally inactivated [15]. Lack or reduced expression levels of the p53 protein seems to be associated with a defective apoptotic response to genotoxic damage and, thus, to anticancer agents [16].

Finally, two additional mechanisms seem to play a central role in breast cancer progression and resistance to treatment. The increased expression of survivin, a member of the inhibitor-of-apoptosis (IAP) protein family, has been demonstrated to be associated with resistance to apoptosis [17-19]. It has been reported that survivin and other IAP proteins cooperate to activate kinase cascades which control cell motility, thus stimulating tumour cell invasion and promoting metastasis [19]. Survivin is indeed overexpressed in most cancer cells and tissues of different histological origin, being correlated to overall survival and acting as a poor prognostic factor in some cancer patients [20-22]. In breast carcinomas, the up-regulation of survivin has been hypothesized to act as a factor exerting resistance against tamoxifen-induced apoptosis $[23,24]$. The second additional mechanism involved in breast cancer pathogenesis includes an increased activity of the human homologue of the Drosophila prune (h-prune), which belongs to a superfamily of phosphoesterases [25]. It has been demonstrated that h-prune is able to promote cell motility through either induction of its phosphodiesterase activity (very recently, a multi-domain adaptor protein, ASAP1, has been reported to stimulate the h-prune phosphodiesterase activity [26]) or interaction with specific protein partners (mainly, nm23-H1) [27-29]. The $\mathrm{h}$-prune protein has been found expressed at higher levels in breast, colorectal, and gastric carcinomas, participating to the promotion of both tumour invasiveness and metastasis formation [25,27]. In breast cancer, overexpression of $\mathrm{h}$-prune has been demonstrated to be involved in cancer progression, identifying subsets of patients with higher tumour aggressiveness (although it seems to have no role as independent prognostic factor in clinical outcome of patients with invasive breast carcinoma) [30]. As previously demonstrated [25,30], gene amplification may play an important role in inducing overexpression of h-prune among breast cancer patients.

In the present study, we examined the expression of survivin, p53, and $\mathrm{pERK}_{1-2}$ proteins as well as the amplification of CyclinD1 and h-prune genes in a well-characterized cohorts of patients with $\mathrm{T} 4$ breast carcinoma and a long follow-up, in order to determine their association with clinical and pathological parameters as well as with patients' outcome.

\section{Methods}

\section{Cases and tissue samples}

Paraffin-embedded samples of 53 consecutive patients with T4 breast cancer were included into the study. Cases were enrolled between 1992 and 2001, and observed up to September 2008 for a median of 125 months (range, 82-194). Patients were assessed by physical examination and mammography, confirmed via coreneedle biopsy. All patients completed a treatment plan including primary chemotherapy, surgery, radiation therapy, adjuvant chemotherapy, and hormone therapy, when indicated (see below). The median age was 51

Table 1 Patient and tumour characteristics at baseline

\begin{tabular}{|c|c|c|}
\hline \multirow[t]{2}{*}{ Characteristics } & \multicolumn{2}{|c|}{ Patients } \\
\hline & $\mathrm{N}$ & $\%$ \\
\hline \multicolumn{3}{|l|}{ Age } \\
\hline$<50$ & 23 & 43 \\
\hline$>50$ & 30 & 57 \\
\hline \multicolumn{3}{|l|}{ Tumor stage } \\
\hline T4abc & 38 & 72 \\
\hline $\mathrm{T} 4 \mathrm{~d}$ & 15 & 28 \\
\hline \multicolumn{3}{|c|}{ Axillary lymph nodes } \\
\hline No & 0 & 0 \\
\hline $\mathrm{N}+$ & 53 & 100 \\
\hline \multicolumn{3}{|c|}{ Hormone receptor status } \\
\hline $\mathrm{ER}+/ \mathrm{ER}-$ & $28 / 25$ & $53 / 47$ \\
\hline $\mathrm{PR}+/ \mathrm{PR}-$ & $17 / 36$ & $32 / 68$ \\
\hline \multicolumn{3}{|c|}{ Proliferative index } \\
\hline Ki67+ & 17 & 32 \\
\hline Ki67- & 27 & 51 \\
\hline unknown & 9 & 17 \\
\hline \multicolumn{3}{|c|}{ Tumour Grading } \\
\hline G2/G3 & $38 / 15$ & $72 / 28$ \\
\hline \multicolumn{3}{|l|}{ HER2 status } \\
\hline HER2+ & 10 & 19 \\
\hline HER2- & 43 & 81 \\
\hline
\end{tabular}


years (range, 32-67). Baseline characteristics are summarized in Table 1.

Fifteen patients $(28 \%)$ had initially inflammatory breast carcinoma (T4d) and 38 (72\%) had initially non-inflammatory cancer (T4abc); all patients had clinical involvement of axillary limph nodes (as $\mathrm{N}+$ ). According to the American Joint Committee on Cancer (AJCC) TNM staging system [1], all 53 cases included into this study were classified with the highest stage of non-metastatic disease (Stage IIIB). Estrogen (ER) and progesterone (PR) status was assessed by standard immunohistochemistry; nuclear staining in $\geq 10 \%$ was considered positive (according to the indication that a significant difference in 5-year recurrence-free survival between ER-positive and ER-negative patients has been reported for a cut-off of $10 \%$ [31]). HER2 status was assessed by fluorescence in situ hybridization (FISH) analysis.

The study was approved by the Institutional Review Board at the University of Cagliari. A written informed consent was obtained for using tissue specimens in molecular analyses.

\section{Treatment plan}

All patients were treated with primary chemotherapy using anthracyline-containing regimens, such as FEC (5Fluorouracil; Epirubicin; Cyclophosphamide) or PEV (Cisplatin; Epirubicin; Vinorelbine). After completing the neoadjuvant chemotherapy, patients underwent surgery consisting of modified radical mastectomy (MRM) or breast-conserving surgery (BCT). Postoperative adjuvant chemotherapy consisted of six cycles of CMF (cyclophosphamide, methotrexate, fluorouracil). Locoregional radiotherapy was performed during the fourth course of CMF. After completing adjuvant chemotherapy, patients with hormone receptor-positive tumours received tamoxifen for 5 years.

Clinical evaluations were performed every 3 months for 2 years and every 6 months thereafter. Instrumental examinations (e.g., mammography, liver ultrasound, chest X-ray, bone scan, and echocardiogram) were performed every 6 months for the first 2 years, and every 12 months thereafter.

\section{Response Assessment}

The clinical measurement of the response to neoadjuvant therapy was defined according to the International Union Against Cancer (UICC) criteria [32]. Pathological complete response (pCR) was defined as the histological absence of residual invasive disease in both the breast and the axilla. Presence of histological invasive residual disease in breast tissue or detection of cancer-positive lymph nodes in the axilla were defined as $<\mathrm{pCR}$. Major pathological response $(\mathrm{MpR})$ in breast tissue was defined as no more than $2 \mathrm{~cm}$ of residual disease (pT0 plus pT1) [27].

\section{Immunohistochemistry (IHC)}

Immunohistochemical staining was done on formalinfixed, paraffin-embedded sections, as previously described [30]. Four- to five-micrometer sections were immunostained with each specific monoclonal antibody (anti-survivin, anti-p53, and anti-phosphorilated ERK $1-2$ ). Slides were viewed using a BX61 Olympus Microscope supplied with DP50 camera and Viewfinder Lite 1.0 Version (Pixera Corporation) image analysis system. Labelling intensity and cellular staining was independently evaluated by two observers. Intensity and distribution of IHC staining was used to classify samples as positive (tissue sections presenting strong to moderate staining in more than $10 \%$ of cells) or negative (including tissue sections showing weak to absent staining) for expression of candidate genes.

\section{Fluorescence in situ Hybridization (FISH)}

For h-prune and CyclinD1 gene amplification analysis, double-colour FISH analysis was performed using the PAC 279-H19 clone, spanning the $h$-prune gene region at chromosome 1q21, and the BAC RP11-300I6 clone specific for the CyclinD1 gene at chromosome 11q13, according to previously reported protocols $[25,30]$. Nuclei were counterstained with 4',6-diamidino-2-phenyl-indole (DAPI). Three distinct experiments were performed for each case. Digital images were captured using an Olympus BX-61 epifluorescence microscope, equipped with the appropriate filters, a $\mathrm{COHU}$ video, and the Cytovision software.

Hybridization signals on at least 100 intact, well-preserved, and non-overlapping nuclei were evaluated by at least two investigators. A gain of gene copy was defined as presence of multiple (three or more) signals in at least $10 \%$ of nuclei

\section{Statistical analysis}

Chi-square and Fisher's exact tests were used to evaluate possible associations between covariates (ER; PR; Ki67 proliferative index; HER2; expression for survivin, p53, and phosphorilated $\mathrm{ERK}_{1-2}$; amplification of h-prune and Cyclind1) and clinical outcome in terms of treatment responses and median survivals. Univariate correlations between prognostic variables and survival outcomes were carried out using the Kaplan-Meier method. Variables were also evaluated for independent correlations on survival by Cox regression analysis. Statistical comparisons were performed using the SPSS statistical software package, version 15.0 (SPSS Inc., Chicago, IL, USA). All tests were two-tailed and 
$P$ values of less than 0.05 were considered to be statistically significant.

\section{Results \\ Patients' collection}

To evaluate the pathogenetic and prognostic roles of five candidate molecular markers (expression levels of survivin, $\mathrm{p} 53$, and pERK1-2 proteins; amplification of CyclinD1 and h-prune genes), we have examined fiftythree patients with diagnosis of $\mathrm{T} 4$ breast carcinoma (T4-N0-2-M0, according to the TNM classification by Sobin et al. [1]).

All patients were evaluated for response to primary chemotherapy. No disease progression was observed during the treatment. The clinical response rate was 100\% (95\% CI, 65,2-89,5): a complete clinical response was observed in 8 patients (15\%). According to Sataloff's classification [33], pathological complete response in primary tumour (pCR) was observed in 8 patients $(15 \%)$; major pathological response $(\mathrm{MpR})$, corresponding to pT0-pT1 classification after primary chemotherapy, was observed in 18 (34\%) breast tissues. The pathological lymph node assessment revealed absence of involvement (pN0) in 12 (23\%) patients after primary chemotherapy.

All 53 patients became suitable for surgery. Modified radical mastectomy was performed in 36 patients $(68 \%)$ and breast conserving treatment (BCT) was feasible in 17 patients (32\%). Records of the clinical follow-up covered a median period of 125 months (range 70-182); 10year disease-free survival (DFS) and overall survival (OS) within the entire series were $32 \%$ and $43 \%$, respectively.

\section{Immunohistochemistry and FISH analysis}

Assessment of the expression levels of survivin, p53, and pERK $1-2$ proteins by immunohistochemistry (IHC) as well as characterization of the chromosomal copy number of cyclinD1 and h-prune genes by fluorescence in situ hybridization (FISH) analysis was carried out on paraffin-embedded tissue sections from primary breast carcinomas of our series.

For IHC analysis, a lack of expression for the p53 protein was observed in 13/53 (25\%) patients; conversely, a positive immunostaining was detected in 5/53 (9\%) cases for pERK $_{1-2}$, and 21/53 (40\%) cases for survivin (Table 2). The FISH analysis was performed using specific probes corresponding to the h-prune and cyclinD 1 genomic regions at chromosomes $1 \mathrm{q} 21$ and $11 \mathrm{q} 13$ (respectively) as well as control clones spanning the peri-centromeric regions at chromosomes 1 and 11, respectively. Multiple FISH signals in $>10 \%$ analyzed nuclei were found in $8 / 53(15 \%)$ cases, for $h$-prune, and 12/53 (23\%) cases, for cyclinD1 (Table 2). A normal copy number (diploid signals) was detected for centromeric control probes, confirming the specificity of the amplification at 1q21 and 11q13 loci and excluding any procedure artifact. Absence of karyotypic anomalies in cells from normal tissues surrounding the tumours strongly indicated that amplification of the $h$-prune and cyclinD1 genomic regions was highly specific for breast cancer cells. Representative examples of IHC staining and FISH results are shown in Figure 1.

\section{Correlation with clinico-pathological parameters}

Using Pearson's Chi-Squared test, molecular alterations were evaluated for association with histological tumour characteristics: ER and PR status, HER2 amplification, Ki67 proliferation index. No statistically significant correlation between any of the molecular alteration and pathological parameters was observed (including triple negative tumours: ER-, PR-, HER2-), with the exception of the detection of positive $\mathrm{pERK}_{1-2}$ immunostaining in the group of patients negative for Ki67 expression only [the pERK $_{1-2}$ expression was not detected in tumours expressing Ki67 (0/16), whereas 4/26 (15\%) Ki67+ tumours presented a positive $\mathrm{pERK}_{1-2}$ immunostaining; $\mathrm{p}=0.041]$ (Table 2).

To investigate the role in predicting the response to primary chemotherapy, all tumour characteristics (histological parameters and molecular alterations) were compared to clinical and pathological outcome in our series. As shown in Table 3, the Ki67 proliferation index and HER2 amplification were significantly associated with a better clinical outcome [5/7 (71\%) complete clinical responses vs. 11/35 (31\%) partial clinical responses, for Ki67 proliferation index; 8/8 (100\%) complete clinical responses vs. 29/45 (64\%) partial clinical responses, for HER2 amplification]. Conversely, the expression of pERK $_{1-2}$ was significantly associated with a worse clinical outcome [0/8 complete clinical response vs. 5/45 (11\%) partial clinical responses] (Table 3). Considering the histological classification, a higher prevalence of positive Ki67 proliferation index was found in cases achieving the pathological response [5/7 (71\%) pCR vs. $11 / 35$ (31\%) non-pCR]; a positive $\mathrm{pERK}_{1-2}$ expression was instead observed in patients who did not achieve the pathological response [0/8 pCR vs. 5/45 (11\%) nonpCR] (Table 3).

Each molecular alteration was then evaluated for its impact on overall survival. Using the Kaplan-Meier method, survival curves indicated that patients carrying pERK $_{1-2}$ positive staining $(\mathrm{p}=0.027)$, h-prune amplification $(\mathrm{p}=0.045)$, and survivin overexpression $(\mathrm{p}=0.008)$ presented a statistically-significant poorer overall survival in comparison with those resulted negative for such alterations (Figure 2A). No significant association with overall survival was observed for p53 down-expression and cyclinD1 amplification (Figure 2A). As summarized in Figure 2B, median overall survivals were consistently 
Table 2 Comparison between IHC or FISH results and histopathological parameters

\begin{tabular}{|c|c|c|c|c|c|c|c|c|c|c|}
\hline \multirow[t]{3}{*}{ Characteristics } & \multicolumn{4}{|c|}{ FISH analysis } & \multicolumn{6}{|c|}{ IHC analysis } \\
\hline & \multicolumn{2}{|l|}{ CyclinD1 } & \multicolumn{2}{|l|}{ h-prune } & \multicolumn{2}{|l|}{ p53 } & \multicolumn{2}{|l|}{ pERK $_{1-2}$} & \multirow{2}{*}{$\begin{array}{r}\text { survivin } \\
\text { positive cases }\end{array}$} & \\
\hline & positive cases & $\%$ & positive cases & $\%$ & positive cases & $\%$ & positive cases & $\%$ & & $\%$ \\
\hline Total patients $(\mathrm{N}=53)$ & 12 & 23 & 8 & 15 & 13 & 25 & 5 & 9 & 21 & 40 \\
\hline \multicolumn{11}{|l|}{ Estrogen receptor (ER) } \\
\hline negative $(N=20)$ & 2 & 10 & 1 & 5 & 4 & 20 & 2 & 10 & 9 & 45 \\
\hline positive ( $\mathrm{N}=24)$ & 7 & 29 & 5 & 11 & 5 & 21 & 2 & 8 & 7 & 29 \\
\hline \multicolumn{11}{|c|}{ Progesterone receptor (PR) } \\
\hline negative $(N=28)$ & 5 & 18 & 2 & 7 & 5 & 18 & 2 & 7 & 13 & 46 \\
\hline positive $(\mathrm{N}=16)$ & 4 & 25 & 4 & 25 & 4 & 25 & 2 & 12 & 3 & 19 \\
\hline \multicolumn{11}{|l|}{ Ki67 } \\
\hline negative $(N=26)$ & 4 & 15 & 3 & 12 & 4 & 15 & 4 & 15 & 11 & 42 \\
\hline positive $(\mathrm{N}=16)$ & 4 & 25 & 2 & 12 & 5 & 31 & 0 & 0 & 5 & 31 \\
\hline \multicolumn{11}{|l|}{ HER2 } \\
\hline $0-1(N=16)$ & 5 & 31 & 3 & 19 & 2 & 12 & 2 & 12 & 9 & 56 \\
\hline $2-3(N=37)$ & 7 & 19 & 5 & 14 & 11 & 30 & 3 & 8 & 12 & 32 \\
\hline
\end{tabular}

higher in breast cancer patients with absence of $h$-prune amplification (median OS: 96 months in comparison to 59 months of patients with h-prune polysomy) and negative immunostaining for $\mathrm{pERK}_{1-2}$ (median OS: 95 months in comparison to 43 months of patients with pERK1-2+ tumours) and survivin (median OS: 97 months in comparison to 45 months of patients with survivin overexpression).

Using the Cox model adjusted according to age at diagnosis for a multivariate analysis, pathological response to primary chemotherapy and survivin overexpression remained the only parameters with a significant impact on prognosis in our series of breast cancer patients; no other association with overall survival was observed for the remaining variables (Table 4).

\section{Discussion}

In this study, we evaluated the impact of some specific molecular alterations (activation of ERK1-2 proteins, amplification of CyclinD1 and h-prune genes, silencing of TP53 gene, overexpression of survivin protein) as predictive and prognostic factors among patients with $\mathrm{T} 4$ breast carcinoma. The analyzed molecular alterations have been largely demonstrated to play an important role in: a) deregulating the cell cycle with subsequent induction of abnormal cell proliferation and tumour growth (ERK1-2 phosphorilation and CyclinD1 amplification); $b$ ) impairing the apoptotic machinery with subsequent induction of resistance to anticancer agents (p53 downexpression and survivin overexpression); and c) promoting metastasis formation (h-prune amplification). Our findings indicated that subsets of T4 breast cancer patients with $\mathrm{pERK}_{1-2}$ staining, survivin expression, or $h$-prune amplification in primary tumour tissues presented a worse overall survival. After multivariate analysis, the pathological response to primary chemotherapy and the survivin overexpression in primary carcinoma represented the main parameters with a role as independent prognostic factors predicting the clinical outcome in such a series of breast cancer patients.

Although an increased expression of survivin in tumour tissues has been already demonstrated to correlate with a poor clinical outcome in a variety of malignancies [20-22], our results clearly indicated an analogous significant impact on prognosis of such a molecular alteration among T4 breast cancer patients. From the pathogenetic point of view, survivin has been found to provide protection against apoptotic stimuli by inhibiting activation of caspase-9 toward the initiation of the intrinsic mitochondrial pathway of apoptosis [18]. Recently, it has been demonstrated that survivin as well as other members of the IAP protein family are strongly involved in metastasis formation; search for survivinIAP antagonists may indeed provide new antimetastatic therapies for cancer patients [19]. Nevertheless, survivin seems to be upregulated through the activation of the MAPK-ERK pathway [34]; in other words, the overexpression of survivin may be associated with the increased levels of ERK1-2 phosphorylation (in our series, all 5 cases expressing $\mathrm{pERK}_{1-2}$ proteins also presented survivin overexpression). Interestingly, our findings indicated that presence of $\mathrm{pERK}_{1-2}$ expression in primary $\mathrm{T} 4$ carcinomas may be indeed correlated with clinical outcome (see Figure 2), suggesting that the cascade of molecular events activating ERK1-2 and upregulating survivin has indeed an important prognostic role in such patients. One could speculate that the lack of a significant association with prognosis for 

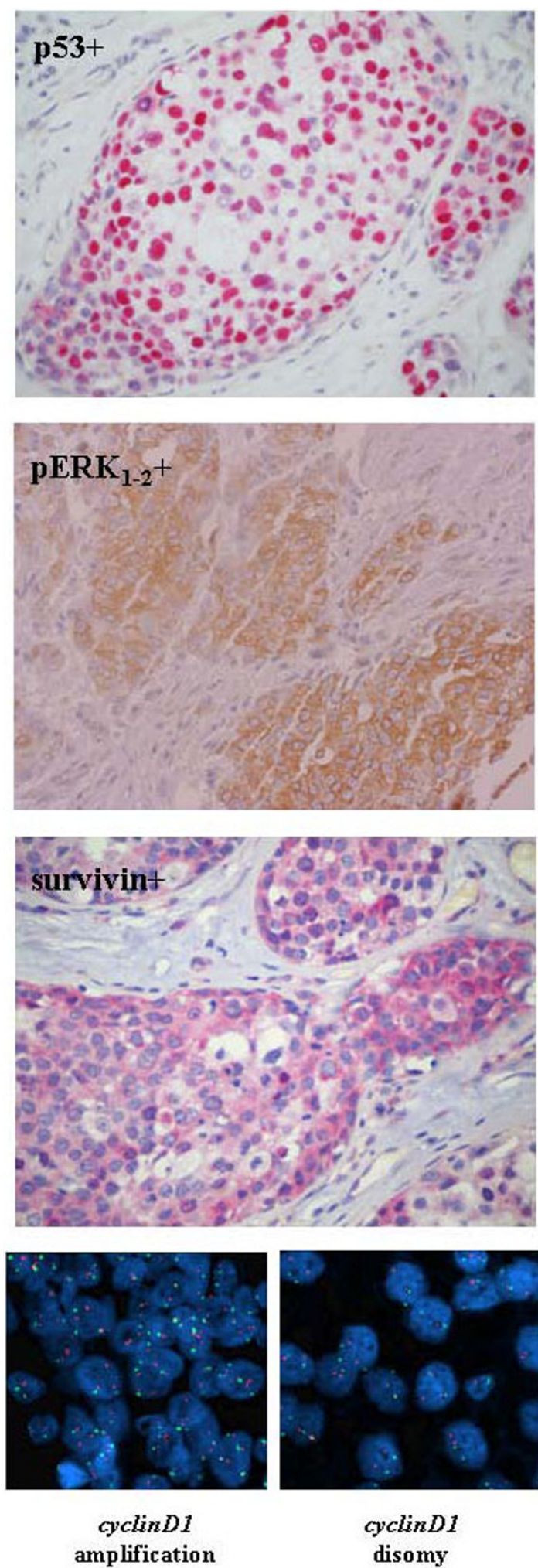

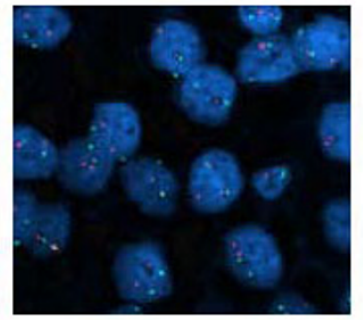

$\operatorname{cyclin} D 1$ disomy
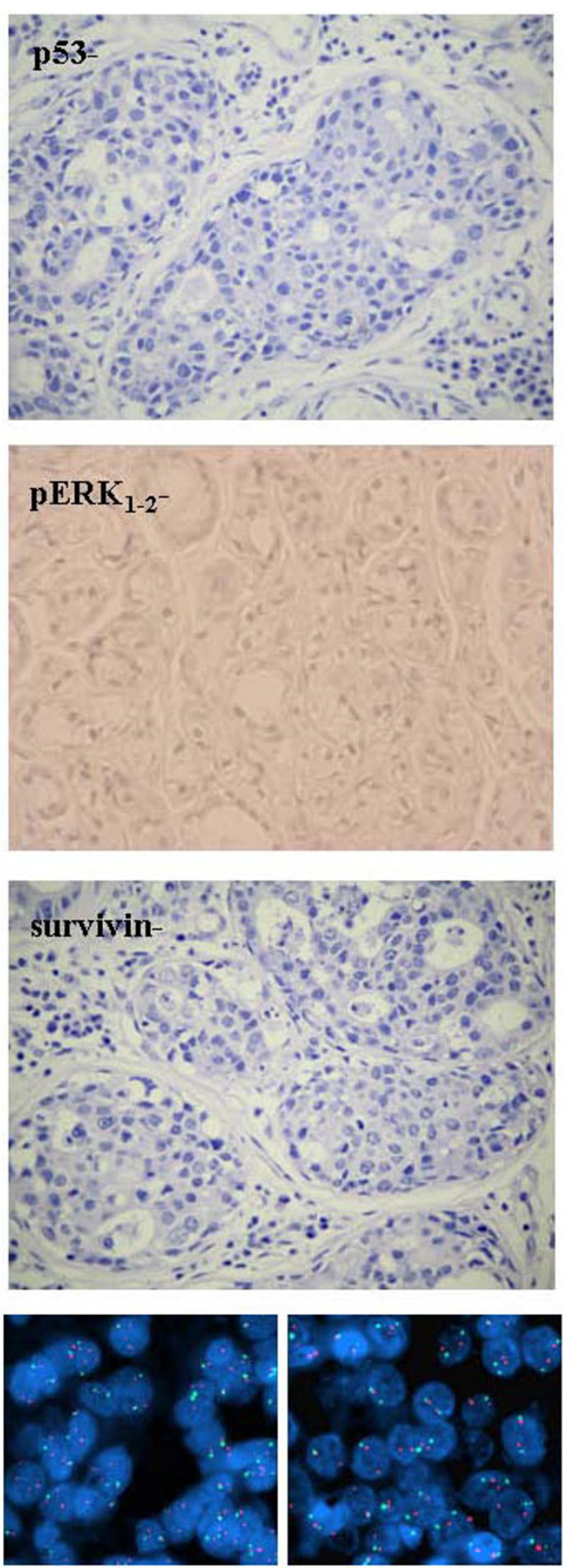

h-prune amplification

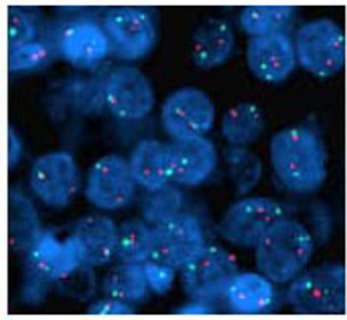

\section{h-prune} disomy

Figure 1 Immunohistochemistry and FISH analysis. (Up-middle) Typical examples of T4 breast carcinoma tissue sections positive (left) or negative (right) for p53, pERK ${ }_{1-2}$, and survivin protein expression. (Bottom) Typical examples of double-colour FISH results. Nuclei extracted from paraffin-embedded tissues after hybridization with probes specific for cyclinD1 or $h$-prune loci (red signals) and control chromosome centromeres (green signals). 
Table 3 Comparison between histopathological or molecular parameters and response to therapy

\begin{tabular}{|c|c|c|c|c|c|c|c|c|c|c|c|c|c|c|c|}
\hline \multicolumn{16}{|l|}{$A$} \\
\hline \multirow[t]{2}{*}{ Outcome } & \multicolumn{3}{|c|}{$E R$} & \multicolumn{3}{|c|}{$P R$} & \multicolumn{3}{|c|}{ Ki67 } & \multicolumn{3}{|c|}{ HER2 } & & & \\
\hline & positives & $\%$ & $P$ & positives & $\%$ & $P$ & positives & $\%$ & $P$ & positives & $\%$ & $P$ & & & \\
\hline Clinical response & & & 0.132 & & & 0.640 & & & 0.047 & & & 0.022 & & & \\
\hline Complete response & $3 / 7$ & 43 & & $3 / 7$ & 43 & & $5 / 7$ & 71 & & $8 / 8$ & 100 & & & & \\
\hline Partial response & $16 / 29$ & 55 & & $11 / 29$ & 38 & & $9 / 27$ & 33 & & $27 / 37$ & 73 & & & & \\
\hline$<$ Partial response & $5 / 8$ & 62 & & $2 / 8$ & 25 & & $2 / 8$ & 25 & & $2 / 8$ & 25 & & & & \\
\hline Pathological response & & & 0.469 & & & 0.235 & & & 0.042 & & & 0.095 & & & \\
\hline $\mathrm{pCR}$ & $4 / 7$ & 57 & & $3 / 7$ & 43 & & $5 / 7$ & 71 & & $7 / 8$ & 87 & & & & \\
\hline$<p C R$ & $20 / 37$ & 54 & & $13 / 37$ & 35 & & $11 / 35$ & 31 & & $30 / 45$ & 67 & & & & \\
\hline \multicolumn{16}{|l|}{ D } \\
\hline \multirow[t]{2}{*}{ Outcome } & \multicolumn{3}{|c|}{ cyclinD1 } & \multicolumn{3}{|c|}{ h-prune } & \multicolumn{3}{|c|}{ pERK $_{1-2}$} & \multicolumn{3}{|c|}{ p53 } & \multirow{2}{*}{\multicolumn{3}{|c|}{ survivin }} \\
\hline & positives & $\%$ & $P$ & positives & $\%$ & $P$ & positives & $\%$ & $P$ & positives & $\%$ & $P$ & & & \\
\hline Clinical response & & & 0.457 & & & 0.824 & & & 0.032 & & & 0.391 & & & 0.089 \\
\hline Complete response & $1 / 8$ & 12 & & $1 / 8$ & 12 & & $0 / 8$ & 0 & & $1 / 8$ & 12 & & $1 / 8$ & 12 & \\
\hline Partial response & $8 / 37$ & 22 & & $5 / 37$ & 14 & & $3 / 37$ & 8 & & $10 / 37$ & 27 & & $15 / 37$ & 41 & \\
\hline$<$ Partial response & $3 / 8$ & 37 & & $2 / 8$ & 25 & & $2 / 8$ & 25 & & $2 / 8$ & 25 & & $5 / 8$ & 62 & \\
\hline Pathological response & & & 0.660 & & & 0.822 & & & 0.007 & & & 0.972 & & & 0.234 \\
\hline $\mathrm{pCR}$ & $2 / 8$ & 25 & & $1 / 8$ & 12 & & $0 / 8$ & 0 & & $2 / 8$ & 25 & & $3 / 8$ & 37 & \\
\hline$<p C R$ & $10 / 45$ & 22 & & $7 / 45$ & 16 & & $5 / 45$ & 11 & & $11 / 45$ & 24 & & $18 / 45$ & 40 & \\
\hline
\end{tabular}

$\mathrm{pCR}$, pathological complete response

pERK $_{1-2}$ staining in multivariate analysis may be due to the fact that we identified only a limited fraction $(5 / 53$; 9\%) of carriers and, thus, the subgroup analysis relied on a small number of subjects.

The well-established prognostic factors currently used into the management of breast cancer patients include the disease stage as well as the degree of differentiation (tumour grade), the proliferation index, and the hormone receptor status (ER, PR, and, recently, HER2) in primary tumours $[35,36]$. In our series of patients with T4 breast carcinoma, no statistically-significant correlation between any of the analyzed molecular alterations and such pathological parameters was inferred. The only exception was represented by the correlation between the $\mathrm{pERK}_{1-2}$ staining and the Ki67 proliferation index. None of the tumours expressing a high Ki67 proliferation index showed an increased level of $\mathrm{pERK}_{1-2}$ protein; conversely, all cases with activated $\mathrm{ERK}_{1-2}$ protein presented a low Ki67 proliferation index. Activation of ERK1-2 proteins has been demonstrated to promote cell cycle progression, participating to induction of cell growth and enhancement of cell survival [10]. Our findings led us to speculate that: a) induction of cell proliferation via $\mathrm{pERK}_{1-2}$ and Ki67 molecules may represent two unrelated phenomena; and b) among patients with low Ki67 expression levels (who may have an unfavourable prognosis [37], though the role of Ki67 proliferation index as prognostic and predictive marker is yet to be conclusively defined [38]), the presence of $\mathrm{pERK}_{1-2}$ overexpression seems to identify a subgroup with an even worse prognosis. Taking into consideration the response rates, patients whose tumours had high $\mathrm{Ki} 67$ expression levels or HER2 amplification presented the highest rates of response to primary chemotherapy (for Ki67, a significant association was found with both clinical and pathological responses; for HER2, a significant association was surprisingly observed with clinical response only) (see Table 3). These latter findings are consistent with data previously reported [39-41]. Among the molecular parameters, only $\mathrm{pERK}_{1-2}$ expression seemed to be significantly correlated with response to primary chemotherapy (significant lower rates were observed for both clinical and pathological responses; see Table 3), reflecting the fact that the activation of ERK1-2 proteins may increase the resistance to apoptosis, reducing the sensitivity to chemotherapy [10].

Several mechanisms have been recently described to participate in progression of breast cancer through activation of the h-prune complex. It is now clear the existence of a network of interacting proteins which indeed regulate the phosphodiesterase activity of h-prune, contributing to promote (ASAP1) or inhibit (nm23-H1) either cancer cell motility and tumour adhesiveness in vitro either tumour invasiveness and metastasis formation in vivo [25-29]. The increased expression of hprune protein has been demonstrated to deeply modify this equilibrium of opposite stimuli, playing an important role in promotion of cancer progression [25]. Among others, the main mechanism leading to h-prune overexpression is represented by the amplification of 


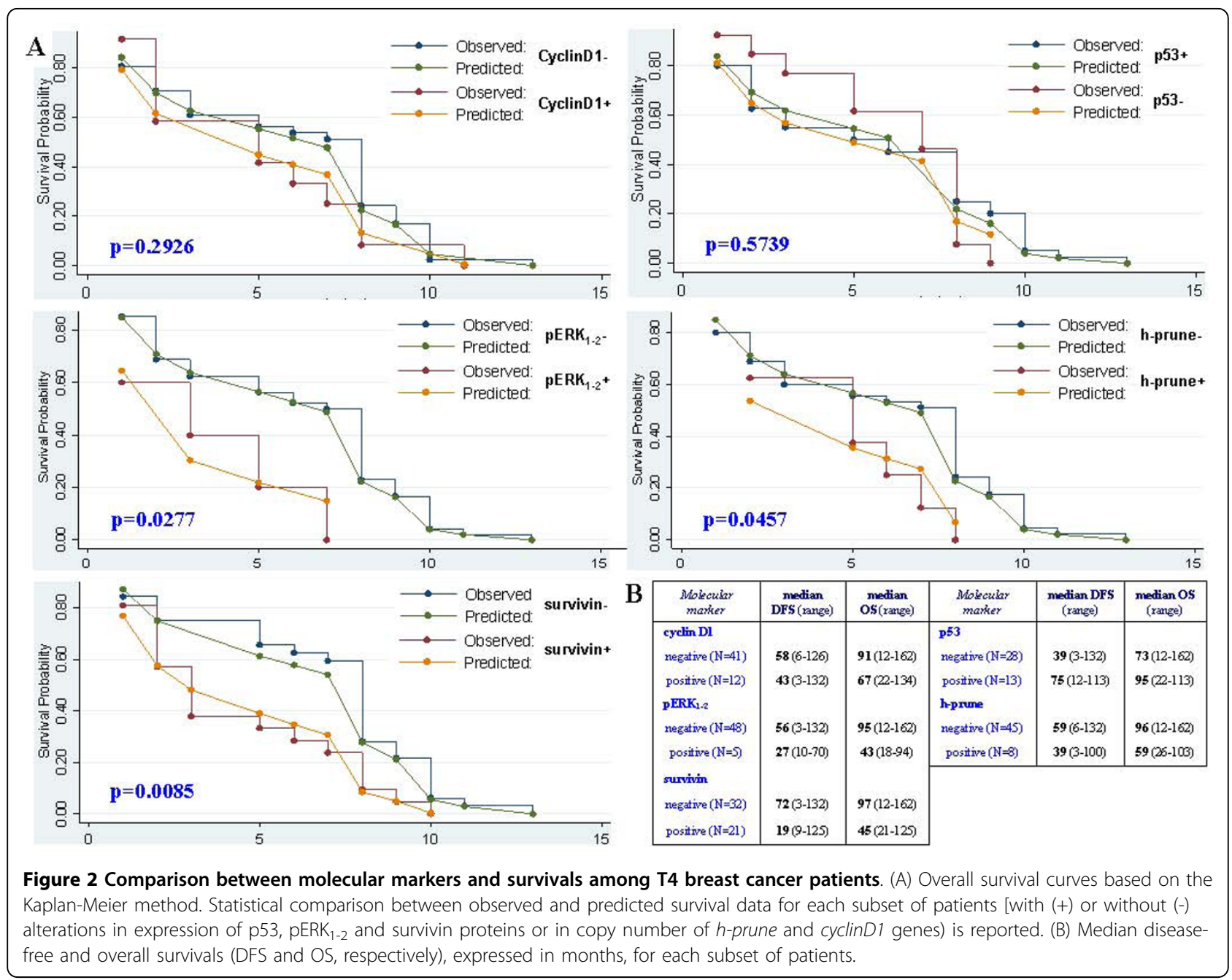

gene copy number [25,42]. Considering tumours with at least three gene copies, a small fraction $(8 / 53 ; 15 \%)$ of T4 breast carcinomas from our series presented $h$-prune amplification at chromosome 1q21.3 (see Table 2); such a frequency is quite identical to that described in our

Table 4 Multivariate analysis of different parameters for overall survival

\begin{tabular}{cccc}
\hline Characteristic & Hazard Ratio & $\mathbf{9 5 \% ~ C l}$ & $\boldsymbol{P}$ \\
\hline cyclinD1 & 0.75 & $0.26-2.12$ & 0.591 \\
h-prune & 2.37 & $0.85-7.03$ & 0.078 \\
pERK $_{1-2}$ & 1.08 & $0.37-3.18$ & 0.875 \\
p53 & 0.74 & $0.34-1.58$ & 0.443 \\
survivin & $\mathbf{3 . 4 0}$ & $\mathbf{1 . 2 0 - 4 . 7 6}$ & $\mathbf{0 . 0 1 2}$ \\
estrogen receptor (ER) & 1.88 & $0.57-6.91$ & 0.281 \\
progesterone receptor (PR) & 1.33 & $0.36-4.84$ & 0.639 \\
proliferation index (Ki67) & 1.81 & $0.48-6.85$ & 0.377 \\
HER2 & 3.24 & $0.96-14.5$ & 0.059 \\
pathological response & $\mathbf{8 . 8 3}$ & $\mathbf{1 . 1 0 - 5 0 . 2}$ & $\mathbf{0 . 0 4 0}$ \\
\hline Stratified by age.
\end{tabular}

previous report $(173 / 1,016 ; 17 \%)$ [30]. All breast cancer patients included into the present study showed axillary nodal involvement; among them, occurrence of $h$-prune amplification was able to identify a subset with a worse overall survival (see Figure 2). As for $\mathrm{pERK}_{1-2}$ staining, the low number of events could explain the absence of a significant association of the h-prune amplification with prognosis in the multivariate analysis.

\section{Conclusions}

Although our study was retrospective, some important indications about either the prediction of the response to therapy or the role on prognosis in T4 breast cancer patients have been inferred. There is no doubt that the pathological response after primary chemotherapy remains one of the major predictor of survival; however, the molecular marker represented by survivin overexpression may be also considered as a useful prognostic factor in these patients. To validate the incorporation of survivin or the other promising molecular parameters 
(h-prune and $\mathrm{pERK}_{1-2}$ ) as markers for management of T4 patients, further large prospective studies are awaited. Nevertheless, translational studies investigating additional molecular biomarkers should contribute to more accurately identify subsets of patients who would be expected to be more or less likely to respond to specific therapeutic interventions.

\section{List of abbreviations}

AJCC: American Joint Committee on Cancer; ER; Estrogen Receptor; FISH: fluorescence in situ hybridization; $1 \mathrm{HC}$ : immunohistochemistry; MAPK. mitogen activated protein kinase; PR: Progesterone Receptor; UICC: International Union Against Cancer.

\section{Competing interests}

The authors declare that they have no competing interests.

\section{Authors' contributions}

BM conceived of the study. MS performed molecular analysis. MB performed statistical analysis. FA participated to collection of cases. MD participated to collection of cases. VP participated to collection of cases. MP performed molecular analysis. PS participated to interpretation of results. AC participated to data management. GrP performed some molecular analyses. $\mathrm{Ml}$ participated to design of the study. GiP participated to interpretation of data and drafted the manuscript.

All authors read and approved the final manuscript.

\section{Acknowledgements}

Authors are grateful to patients for their important contribution to this study. Work was supported by Italian Ministry of Health "Progetto Ricerca Finalizzata", Sardinia Regional Government (Regione Autonoma della Sardegna), and Associazione UMANA Onlus.

\section{Author details}

'Department of Medical Oncology, University of Cagliari, Cagliari, Italy. ${ }^{2}$ Institute of Biomolecular Chemistry-National Research Council (CNR), Sassari, Italy. ${ }^{3}$ Epidemiology Unit, Azienda Sanitaria Locale 1, Sassari, Italy. ${ }^{4}$ Department of Cytomorphology, Cagliari University, Cagliari, Italy. ${ }^{5}$ Institute of Pathology, Azienda Ospedaliero Universitaria, Sassari, Italy.

Received: 5 March 2010 Accepted: 24 August 2010

Published: 24 August 2010

\section{References}

1. Sobin L, Wittekind C, (eds): TNM classification of malignant tumors John Wiley \& Sons, New York, 62002.

2. Singletary SE, Allred C, Ashley P, Bassett LW, Berry D, Bland KI, Borgen PI, Clark G, Edge SB, Hayes DF, Hughes LL, Hutter RV, Morrow M, Page DL, Recht A, Theriault RL, Thor A, Weaver DL, Wieand HS, Greene FL: Revision of the American Joint Committee on Cancer staging system for breast cancer. J Clin Oncol 2002, 20:3628-36.

3. Woodward WA, Strom EA, Tucker SL, McNeese MD, Perkins GH, Schechter NR, Singletary SE, Theriault RL, Hortobagyi GN, Hunt KK, Buchholz TA: Changes in the 2003 American Joint Committee on Cancer staging for breast cancer dramatically affect stage-specific survival. J Clin Oncol 2003, 21:3244-8.

4. Subramaniam DS, Isaacs C: Utilizing prognostic and predictive factors in breast cancer. Curr Treat Options Oncol 2005, 6:147-159.

5. Hayes DF: Prognostic and predictive factors revisited. Breast 2005, 14:493-499.

6. Van Laere S, Van der Auwera I, Van den Eynden G, Van Hummelen P, van Dam $P$, Van Marck E, Vermeulen PB, Dirix L: Distinct molecular phenotype of inflammatory breast cancer compared to non-inflammatory breast cancer using Affymetrix-based genome-wide gene-expression analysis. Br J Cancer 2007, 97:1165-1174.

7. Santen RJ, Song RX, McPherson R, Kumar R, Adam L, Jeng MH, Yue W: The role of mitogen-activated protein (MAP) kinase in breast cancer. J Steroid Biochem Mol Biol 2002, 80:239-256.
8. Eralp Y, Derin D, Ozluk Y, Yavuz E, Guney N, Saip P, Muslumanoglu M, Igci A, Kücücük $S$, Dincer $M$, Aydiner $A$, Topuz E: MAPK overexpression is associated with anthracycline resistance and increased risk for recurrence in patients with triple-negative breast cancer. Ann Oncol 2008, 19:669-74.

9. McGlynn LM, Kirkegaard T, Edwards J, Tovey S, Cameron D, Twelves C, Bartlett JM, Cooke TG: Ras/Raf-1/MAPK pathway mediates response to tamoxifen but not chemotherapy in breast cancer patients. Clin Cancer Res 2009, 15:1487-95.

10. Davies H, Bignell GR, Cox C, Stephens P, Edkins S, Clegg S, Teague J, Woffendin H, Garnett MJ, Bottomley W, Davis N, Dicks E, Ewing R, Floyd Y, Gray K, Hall S, Hawes R, Hughes J, Kosmidou V, Menzies A, Mould C, Parker A, Stevens C, Watt S, Hooper S, Wilson R, Jayatilake H, Gusterson BA, Cooper C, Shipley J, Hargrave D, Pritchard-Jones K, Maitland N, ChenevixTrench G, Riggins GJ, Bigner DD, Palmieri G, Cossu A, Flanagan A, Nicholson A, Ho J, Leung SY, Yuen ST, Weber BL, Seigler HF, Darrow TL, Paterson H, Marais R, Marshall CJ, Wooster R, Stratton MR, Futreal PA: Mutations of the BRAF gene in human cancer. Nature 2002, 417:949-954.

11. McCubrey JA, Steelman LS, Abrams SL, Lee JT, Chang F, Bertrand FE, Navolanic PM, Terrian DM, Franklin RA, D'Assoro AB, Salisbury JL, Mazzarino MC, Stivala F, Libra M: Roles of the RAF/MEK/ERK and PI3K/ PTEN/AKT pathways in malignant transformation and drug resistance. Adv Enzyme Regul 2006, 46:249-279.

12. Deng $Q$, Liao $R, W u B L$, Sun $P$ : High intensity ras signaling induces premature senescence by activating $\mathrm{p} 38$ pathway in primary human fibroblasts. J Biol Chem 2004, 279:1050-1059.

13. Wen-Sheng W: ERK signaling pathway is involved in p15INK4b/p16INK4a expression and HepG2 growth inhibition triggered by TPA and Saikosaponin a. Oncogene 2003, 22:955-963.

14. Vogelstein B, Kinzler KW: Cancer genes and the pathways they control. Nat Med 2004, 10:789-799.

15. Pomerantz J, Schreiber-Agus N, Lié geois NJ: The Ink4a tumor suppressor gene product, 19Arf, interacts with MDM2 and neutralizes DM2's inhibition of p53. Cell 1998, 92:713-723.

16. Levesque AA, Eastman A: p53-based cancer therapies: Is defective p53 the Achilles heel of the tumor? Carcinogenesis 2007, 28:13-20.

17. Li F, Ambrosini G, Chu EY, Plescia J, Tognin S, Marchisio PC, Altieri DC: Control of apoptosis and mitotic spindle checkpoint by survivin. Nature 1998, 396:580.

18. Dohi T, Beltrami E, Wall NR, Plescia J, Altieri DC: Mitochondrial survivin inhibits apoptosis and promotes tumorigenesis. J Clin Invest 2004, 114:1117-1127.

19. Mehrotra S, Languino LR, Raskett CM, Mercurio AM, Dohi T, Altieri DC: IAP regulation of metastasis. Cancer Cell 2010, 17:53-64.

20. Kennedy SM, O'Driscoll L, Purcell R, Fitz-Simons N, McDermott EW, Hill AD, O'Higgins NJ, Parkinson M, Linehan R, Clynes M: Prognostic importance of survivin in breast cancer. Br J Cancer 2003, 88:1077-1083.

21. Li YH, Hu CF, Shao Q, Huang MY, Hou JH, Xie D, Zeng YX, Shao JY: Elevated expressions of survivin and VEGF protein are strong independent predictors of survival in advanced nasopharyngeal carcinoma. J Transl Med 2008, 6:1.

22. Augello C, Caruso L, Maggioni M, Donadon M, Montorsi M, Santambrogio R, Torzilli G, Vaira V, Pellegrini C, Roncalli M, Coggi G, Bosari S: Inhibitors of apoptosis proteins (IAPs) expression and their prognostic significance in hepatocellular carcinoma. BMC Cancer 2009, 9:125.

23. Moriai R, Tsuji N, Moriai M, Kobayashi D, Watanabe N: Survivin plays as a resistant factor against tamoxifen-induced apoptosis in human breast cancer cells. Breast Cancer Res Treat 2009, 117:261-71.

24. Span PN, Tjan-Heijnen VC, Manders P, van Tienoven D, Lehr J, Sweep FC: High survivin predicts a poor response to endocrine therapy, but a good response to chemotherapy in advanced breast cancer. Breast Cancer Res Treat 2006, 98:223-230.

25. D'Angelo A, Garzia L, Andrè A, Carotenuto P, Aglio V, Guardiola O, Arrigoni G, Cossu A, Palmieri G, Aravind L, Zollo M: Prune cAMP phosphodiesterase promotes cancer metastasis by down-regulation of nm23-H1. Cancer Cell 2004, 5:137-149.

26. Müller T, Stein U, Poletti A, Garzia L, Rothley M, Plaumann D, Thiele W, Bauer M, Galasso A, Schlag P, Pankratz M, Zollo M, Sleeman JP: ASAP1 promotes tumor cell motility and invasiveness, stimulates metastasis 
formation in vivo, and correlates with poor survival in colorectal cancer patients. Oncogene 2010, 29:2393-403.

27. Marino N, Zollo M: Understanding h-prune biology in the fight against cancer. Clin Exp Metastasis 2007, 24:637-45.

28. Garzia L, D'Angelo A, Amoresano A, Knauer SK, Cirulli C, Campanella C, Stauber RH, Steegborn C, lolascon A, Zollo M: Phosphorylation of nm23$\mathrm{H} 1$ by $\mathrm{CKI}$ induces its complex formation with $\mathrm{h}$-prune and promotes cell motility. Oncogene 2008, 27:1853-64.

29. Galasso A, Zollo M: The Nm23-H1-h-Prune complex in cellular physiology: a 'tip of the iceberg' protein network perspective. Mol Cell Biochem 2009, 329:149-59.

30. Zollo $M$, Andrè $A$, Cossu $A$, Sini MC, D'Angelo A, Marino N, Budroni $M$, Tanda F, Arrigoni G, Palmieri G: Overexpression of h-prune in breast cancer is correlated with advanced disease status. Clin Cancer Res 2005, 11:199-205.

31. Horii R, Akiyama F, Ito $Y$, Iwase T: Assessment of hormone receptor status in breast cancer. Pathol Int 2007, 57:784-790.

32. Hayward JL, Carbone PP, Heusen JC, Kumaoka S, Segaloff A, Rubens RD: Assessment of response to therapy in advanced breast cancer. $\mathrm{Br} J$ Cancer 1977, 35:292-298.

33. Sataloff DM, Mason BA, Prestipino AJ, Seinige UL, Lieber CP, Baloch Z: Pathologic response to induction chemotherapy in locally advanced carcinoma of the breast: a determinant of outcome. J Am Coll Surg 1995, 180:297-306.

34. Siddiqa A, Long LM, Li L, Marciniak RA, Kazhdan I: Expression of HER-2 in MCF-7 breast cancer cells modulates anti-apoptotic proteins Survivin and $\mathrm{BCl}-2$ via the extracellular signal-related kinase (ERK) and phosphoinositide-3 kinase (PI3K) signalling pathways. BMC Cancer 2008, $8: 129$

35. Lønning PE: Breast cancer prognostication and prediction: are we making progress? Ann Oncol 2007, 18(Suppl 8):viii3-7.

36. Rydén L, Landberg G, Stål O, Nordenskjöld B, Fernö M, Bendahl PO: HER2 status in hormone receptor positive premenopausal primary breast cancer adds prognostic, but not tamoxifen treatment predictive, information. Breast Cancer Res Treat 2008, 109:351-357.

37. Jalava P, Kuopio T, Juntti-Patinen L, Kotkansalo T, Kronqvist P, Collan Y: Ki67 immunohistochemistry: a valuable marker in prognostication but with a risk of misclassification: proliferation subgroups formed based on Ki67 immunoreactivity and standardized mitotic index. Histopathology 2006, 48:674-682.

38. Yerushalmi R, Woods R, Ravdin PM, Hayes MM, Gelmon KA: Ki67 in breast cancer: prognostic and predictive potential. Lancet Oncol 2010, 11:174-183.

39. Petit T, Wilt M, Velten M, Millon R, Rodier JF, Borel C, Mors R, Haegelé P, Eber $\mathrm{M}$, Ghnassia JP: Comparative value of tumour grade, hormonal receptors, Ki-67, HER-2 and topoisomerase II alpha status as predictive markers in breast cancer patients treated with neoadjuvant anthracycline-based chemotherapy. Eur J Cancer 2004, 40:205-211.

40. Rouzier R, Perou CM, Symmans WF, Ibrahim N, Cristofanilli M, Anderson $K$, Hess KR, Stec J, Ayers M, Wagner P, Morandi P, Fan C, Rabiul I, Ross JS, Hortobagyi GN, Pusztai L: Breast cancer molecular subtypes respond differently to preoperative chemotherapy. Clin Cancer Res 2005, 11:5678-5685.

41. Colleoni M, Orvieto E, Nolé F, Orlando L, Minchella I, Viale G, Peruzzotti G, Robertson C, Noberasco C, Galimberti V, Sacchini V, Veronesi P, Zurrida S, Orecchia R, Goldhirsch A: Prediction of response to primary chemotherapy for operable breast cancer. Eur J Cancer 1999, 35:574-579.

42. Forus A, D'Angelo A, Henriksen J, Merla G, Maelandsmo GM, Flørenes VA, Olivieri S, Bjerkehagen B, Meza-Zepeda LA, del Vecchio Blanco F, Müller C, Sanvito F, Kononen J, Nesland JM, Fodstad $\varnothing$, Reymond A, Kallioniemi OP, Arrigoni G, Ballabio A, Myklebost O, Zollo M: Amplification and overexpression of PRUNE in human sarcomas and breast carcinomas - a possible mechanism for altering the nm23-H1 activity. Oncogene 2001, 20:6881-6890.

\section{Pre-publication history}

The pre-publication history for this paper can be accessed here: http://www.biomedcentral.com/1471-2407/10/458/prepub

doi:10.1186/1471-2407-10-458

Cite this article as: Massidda et al:: Molecular alterations in key-regulator genes among patients with T4 breast carcinoma. BMC Cancer 2010 10:458.

\section{Submit your next manuscript to BioMed Central and take full advantage of:}

- Convenient online submission

- Thorough peer review

- No space constraints or color figure charges

- Immediate publication on acceptance

- Inclusion in PubMed, CAS, Scopus and Google Scholar

- Research which is freely available for redistribution 